San Jose State University

SJSU ScholarWorks

Master's Theses

Master's Theses and Graduate Research

1995

\title{
Employment outcomes for individuals with severe and persistent mental illness
}

Susan Renée LeBlanc

San Jose State University

Follow this and additional works at: https://scholarworks.sjsu.edu/etd_theses

\section{Recommended Citation}

LeBlanc, Susan Renée, "Employment outcomes for individuals with severe and persistent mental illness" (1995). Master's Theses. 1154.

DOI: https://doi.org/10.31979/etd.4td2-cwrh

https://scholarworks.sjsu.edu/etd_theses/1154

This Thesis is brought to you for free and open access by the Master's Theses and Graduate Research at SJSU ScholarWorks. It has been accepted for inclusion in Master's Theses by an authorized administrator of SJSU ScholarWorks. For more information, please contact scholarworks@sjsu.edu. 


\section{INFORMATION TO USERS}

This manuscript has been reproduced from the microfilm master. UMI films the text directly from the original or copy submitted. Thus, some thesis and dissertation copies are in typewriter face, while others may be from any type of computer printer.

The quality of this reproduction is dependent upon the quality of the copy submitted. Broken or indistinct print, colored or poor quality illustrations and photographs, print bleedthrough, substandard margins, and improper alignment can adversely affect reproduction.

In the unlikely. event that the author did not send UMI a complete manuscript and there are missing pages, these will be noted. Also, if unauthorized copyright material had to be removed, a note will indicate the deletion.

Oversize materials (e.g., maps, drawings, charts) are reproduced by sectioning the original, beginning at the upper left-hand corner and contimuing from left to right in equal sections with small overlaps. Each original is also photographed in one exposure and is included in reduced form at the back of the book.

Photographs included in the original manuscript have been reproduced xerographically in this copy. Higher quality $6^{\prime \prime} \times 9^{n}$ black and white photographic prints are available for any photographs or illustrations appearing in this copy for an additional charge. Contact UMI directly to order.

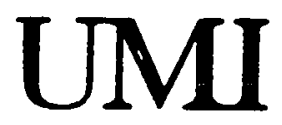

A Bell \& Howell information Company

300 North Zeeb Road. Ann Afbor, MI 48106-1346 USA

$313: 761-4700 \quad 800: 521-0600$ 
$-\quad-\cdots \ldots$ 
EMPLOYMENT OUTCOMES FOR INDIVIDUALS

WITH SEVERE AND PERSISTENT MENTAL ILLNESS

A Thesis

Presented to

The Faculty of the Department of Occupational Therapy

San Jose State University

In Partial Fulfillment

of the Requirements for the Degree

Master of Science

\author{
by \\ Susan Renée LeBlanc \\ December 1995
}


UMI Number: 1377245

OMI Microform 1377245

Copyright 1996, by UMI Company. All rights reserved.

This microform edition is protected against unauthorized copying under Title 17, United States Code.

\section{UMI}

300 North Zeeb Road

Ann Arbor, MI 48103 
(c) 1995

Susan Renée LeBlanc

ALL RIGHTS RESERVED 
APPROVED FOR THE DEPARTMENT OF OCCUPATIONAL THERAPY
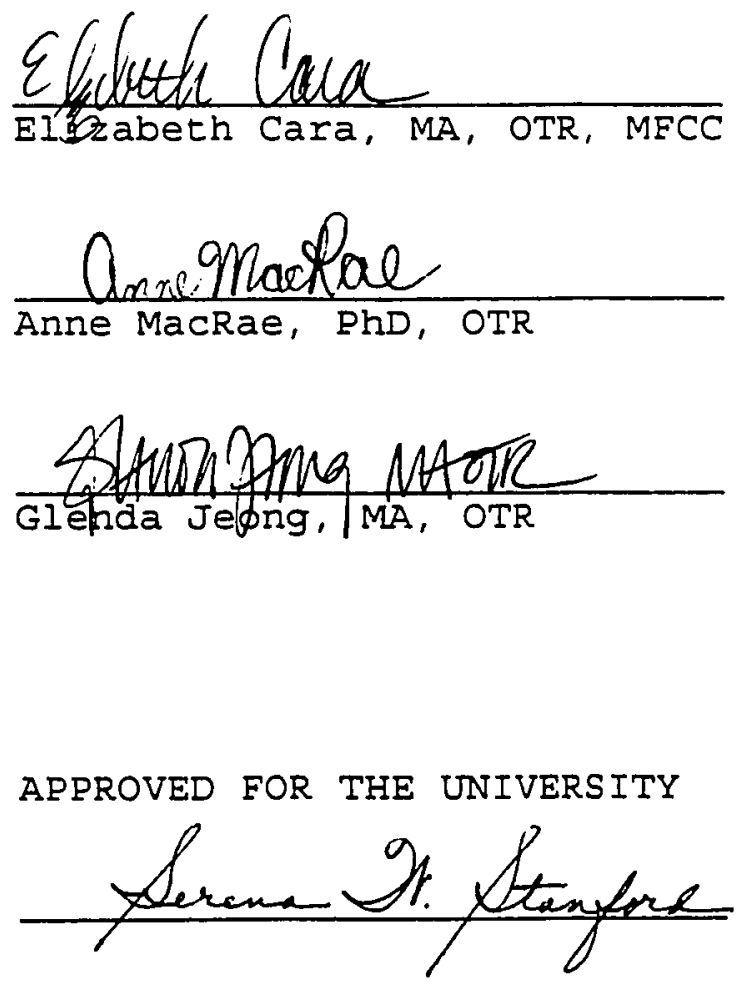


\begin{abstract}
EMPLOYMENT OUTCOMES

FOR ADULTS WITH SEVERE AND PERSISTENT MENTAL ILLNESS

by Susan Renée LeBlanc

This thesis used a chart review methodology to examine
\end{abstract} employment outcomes for 37 adults with severe and persistent mental illness six months prior to utilizing vocational rehabilitation services at Community Vocational

Enterprises/Keystone Vocational Services (CVE/Keystone) and three, six, and nine months after starting the program.

This study evaluated: 1) the number of subjects employed, 2) the rate of employment as measured by the number of work hours per week, 3) the longevity of employment as measured by the duration of time job maintained, 4) the wages earned, and 5) the distribution of Social security benefits.

The results indicated an increase in the number of subjects employed, an increase in the number of work hours per week, and an increase in the amount of wages earned. The longevity of employment also improved after vocational rehabilitation. There was no change in the distribution of Social security benefits. 


\section{ACKNOWLEDGEMENTS}

Much appreciation is extended to my major advisor, Liz Cara, MA, OTR, MFCC for her expertise, guidance, and support. Gratitude is extended to Dr. Anne MacRae and Glenda Jeong, MA, OTR not only for their time and energy in reviewing and editing my thesis but also for instilling in me the professional values inherent in being an occupational therapist. Special appreciation is extended to Heidi Pendleton, MA, OTR for informing me of the Delbecq nominal group process used in this study.

I would like to thank the entire CVE/KVS staff for their unyielding assistance, endless encouragement, and wondrous inspiration. I hope for all of you much success in the future.

Appreciation is extended to my parents for giving me the courage and inspiration to pursue my dreams. Gina, thank you for always believing in me. I wish to send special thanks to my sister Janet, Kevin, Shane and Renee, for without their selflessness, understanding, and thoughtfulness, my graduate pursuits would not have been possible.

I wish to thank my best friend for his counsel, support, understanding, faith, and love. Although miles away, his echoing words of confidence and encouragement always seemed to find their way home. 
TABLE OF CONTENTS

\begin{tabular}{|c|c|}
\hline & Page \\
\hline Abstract & iv \\
\hline Acknowledgments & $\mathrm{v}$ \\
\hline List of Tables & viii \\
\hline Chapter I INTRODUCTION & 1 \\
\hline Purpose & 1 \\
\hline Statement of Problem & 1 \\
\hline Research Questions & 3 \\
\hline Definitions & 4 \\
\hline Significance & 6 \\
\hline Limitations & 7 \\
\hline Assumptions & 8 \\
\hline Chapter 2 REVIEW OF THE LITERATURE & 9 \\
\hline The Meaning of Work & 9 \\
\hline Work For Adults With Severe and & 16 \\
\hline Persistent Mental Illness & \\
\hline Conceptual Framework & 27 \\
\hline Summary & 32 \\
\hline Chapter 3 PROCEDURES AND METHODOLOGY & 34 \\
\hline Purpose & 34 \\
\hline Research Design & 34 \\
\hline Research Questions & 34 \\
\hline Description of the setting & 35 \\
\hline subjects & 37 \\
\hline
\end{tabular}

vi 
Data Collection Instrument 38

Chapter 4 DATA ANALYSIS AND RESULTS 42

$\begin{array}{ll}\text { Population } & 42\end{array}$

Results $\quad 42$

Chapter 5 RESULTS, IMPLICATIONS 58

AND RECOMMENDATIONS, SUMMARY

Results 58

Implications and Recommendations 62

$\begin{array}{ll}\text { Summary } & 65\end{array}$

REFERENCES $\quad 66$

$\begin{array}{ll}\text { APPENDICES } & 73\end{array}$

Appendix A: Sample Instrument 73

$\begin{array}{ll}\text { Appendix B: Instrument } & 76\end{array}$

vii 


\section{LIST OF TABLES}

Table Page

IA Number of Subjects Employed 45

IB Number of Subjects Employed 46

2 Rate of Employment as Measured by the Number of 48 Work Hours Per Week

3 Longevity of Subjects Employed 50

4 Frequency Distribution of Pay Rate of Subjects 54

5 Distribution of Social Security Benefits 57 
CHAPTER 1

INTRODUCTION

Purpose

The purpose of the study was to examine employment outcomes for individuals with severe and persistent mental illness six months prior to utilizing vocational rehabilitation services and three, six, and nine months after starting a program.

Statement of the Problem

The deinstitutionalization movement in the $1960^{\prime} \mathrm{s}$ and $1970^{\prime}$ s resulted in a significantly reduced number of people in state hospitals. Consequently, more adults with severe and persistent mental illness have been living in the community (Stauffer, 1986). Unfortunately, the vast majority of these individuals have difficulty acquiring and maintaining community-based employment (Bond \& Boyer, 1988).

A review of the literature in community mental health, prevocational and vocational rehabilitation, occupational therapy, and the current labor market revealed the need for a more extensive appraisal of community-based employment outcomes for individuals with severe and persistent mental illness (Bond, 1988; Frey, 1994; Stauffer, 1986).

Much information is available regarding the complexity of difficulties experienced by persons with severe and persistent mental illness when attempting to enter or return 
to the work force. Prevalent data is also available regarding psychosocial rehabilitation in hospital-based programs, the employability of individuals with severe and persistent mental illness, the predictability of future work performance, and the varying success in reaching clinical treatment goals and job placement goals in sheltered workshops and clubhouse programs.

Although these studies provide useful information for program planning, treatment direction, and clinical outcome data relating to goal achievement and successful interventions, the data does not proffer significant empirical evidence regarding community-based employment for individuals with severe and persistent mental illness.

The successful vocational rehabilitation of persons with severe and persistent mental illness is a problem in our society (Spooner, Algozzine, \& Saxon, 1980). Currently, some vocational rehabilitation programs exist and the trend in treatment is moving towards vocational rehabilitation. However, vocational rehabilitation as treatment and the success of vocational rehabilitation has not been documented. Therefore, the comprehensive evaluation of successful employment outcomes in the community for individuals with severe and persistent mental illness who have utilized vocational rehabilitation services is a critical area that needs to be examined (Bond, 1987). 
In view of the acknowledged problem area, this study specifically analyzed community-based employment outcomes for adults with severe and persistent mental illness who utilized vocational rehabilitation services delivered by Community Vocational Enterprises/Keystone Vocational Services (CVE/Keystone). The employment outcomes examined included the following multiple measures: frequency of subjects employed, rate of employment as measured by the number of work hours per week, longevity of employment as measured by the duration of time job maintained, amount of wages earned, and variations in distribution of social Security benefits.

\section{Research Questions}

The research was designed to answer the following questions:

1. Is there a change in the number of clients employed six months prior to utilizing service at CVE/Keystone and three, six, and nine months after starting the vocational rehabilitation program?

2 . Is there a change in the rate of employment as measured by the number of work hours per week six months prior to utilizing service at CVE/Keystone and three, six and nine months after starting the vocational rehabilitation program? 3. Is there a change in the longevity of employment as measured by the duration of time job maintained after 
vocational rehabilitation delivered by CVE/Keystone is utilized?

4. Is there a change in the wages earned six months prior to utilizing service at CVE/Keystone and three, six, and nine months after starting the vocational rehabilitation program? 5. Is there a change in the distribution of social security benefits six months prior to utilizing service at CVE/Keystone and three, six, and nine months after starting the vocational rehabilitation program?

Definitions

Definitions of terms used in this study included the following:

Severe and persistent mental illness: certain mental or emotional disorders that erode or prevent appropriate functional development (organic brain syndrome, schizophrenia, mood disorders, and other psychoses and disorders that may become chronic).

Community-based employment: paid employment in the community.

CVE/Keystone: a small vocational rehabilitation agency in San Francisco funded by the city and county of San Francisco and the San Francisco study Center that offers a Transitional Employment Program, Supported Employment, job development, etc., related to maintaining employment. Prevocational rehabilitation: treatment programs focusing on 
prerequisite work skills in the areas of work adjustment training and personal adjustment training. Rate of employment: number of hours employed per week. Social Security Disability Insurance (SSDI): monthly payment for disabled individuals with a work history who have paid into the Social security system. Social Security Income (SSI): monthly cash assistance to needy aged and disabled individuals with little or no work history.

Theoretical models/frames of reference: guiding philosophies used in occupational therapy and in general mental health rehabilitation, including those identified as humanistic, occupational performance, behavioral, occupational behavior, human occupation, rehabilitation, and occupational role acquisition.

Transitional Employment Program (TEP): community-based employment program which focuses on temporary job placement and job training for individuals with severe and persistent mental illness. The program focuses on the development of general work skills by placing participants in part-time, entry level jobs with staff supervision in order to evaluate employability skills and provide a successful work experience (Bond \& Boyer, 1988).

Supported Employment (SE): community-based employment program with on-going, follow-along services for individuals 
with severe and persistent mental illness.

Vocational rehabilitation programs: programs which provide an array of employment skills training, counseling, and support services to assist consumers in obtaining and maintaining community-based employment and remediating deficits in the area of work.

\section{Significance}

The study provided outcome data concerning communitybased employment for individuals with severe and persistent mental illness in an area that demonstrated a need for further investigation. Specifically, the study examined employment outcomes for individuals with severe and persistent mental illness six months prior to utilizing vocational rehabilitation services delivered by CVE/Keystone and three, six, and nine months after starting the program. The number of subjects employed, longevity of employment, rate of employment, wages earned, and variations on distribution of social security benefits were analyzed.

Results of this study were presented to CVE/Keystone to illustrate comprehensive vocational outcomes as they related to community-based employment before and after starting vocational rehabilitation. This information was useful to CVE/Keystone, since outcome documentation and analysis for the agency had not yet been conducted. Furthermore, with the impetus for adopting managed mental health care systems, 
community-based vocational rehabilitation agencies including CVE/Keystone are being forced to provide concrete functional employment outcomes for their programs which demonstrate efficient, quality, and cost-effective service. Without this data, there is a concern that financial support from the city and county of San Francisco may be cut. Hence, CVE/Keystone may use the documented information to analyze the cost effectiveness of service for reference or for viewing by third party payers, managed care organizations, and consumers. Also, the results of the employment outcome study served as an indirect indication for CVE/Keystone as a future representative model of vocational rehabilitation in the City and County of San Francisco Community Mental Health system.

\section{Limitations}

The limitations to this study are as follows:

1. The study is limited to a relatively small sample from one vocational rehabilitation agency in San Francisco and therefore cannot be generalized to the entire population of individuals with severe and persistent mental illness or other vocational rehabilitation centers.

2. The subjects for the study are limited to specific criteria and therefore may not be generalized to the entire population of individuals with severe and persistent mental illness. 
3. The information generated from the non-random sample of convenience used in this study may only partially represent the population with respect to employment outcomes in the community-based job market common to other programs serving individuals with severe and persistent mental illness in the United States.

\section{Assumptions}

This research was based upon the assumption that a selection of patients with various diagnoses listed under one category of severe and persistent mental illness may be evaluated as a homogenous group. It was also assumed that the subjects completed the self-reported work history honestly and accurately. 
CHAPTER 2

REVIEW OF THE LITERATURE

A review of the Iiterature in the areas of community mental health, prevocational and vocational rehabilitation, occupational therapy, and the current labor market reveals the need for a more extensive appraisal of community-based employment outcomes for individuals with severe and persistent mental illness (Bond, 1988; Frey, 1994; Stauffer, 1986).

The Meaning of Work

The concept of work has been a fundamental part of life, health, and human existence for centuries. Changes in its definition and significance in society are illustrated in its application in occupational therapy (Harvey-Krefting, 1985). The historic use and rationale for work as therapy is presented here with emphasis on work as an integral part of the American culture, as a prescription for therapy, as occupation, as employment, and as productivity.

Work as an Integral Part of the American Culture

Job, employment, occupation, profession, vocation, labor, trade, and activity are all words that identify the work concept in our society. The variety of contexts in which people speak of work attest to the belief that this form of human activity is truly a central institution in their lives. During this time frame, work was defined as any 
activity, paid or unpaid, that produces something of value. This definition implies a meaning, a purpose to work. In modern day society, work is defined with considerations for its varying functions in the American culture. Work is said to function as an economic, social, and emotional facilitator (Thornton \& Maynard, 1989). From work, people obtain financial gratification that allows them to satisfy both needs and wants that may otherwise be unobtainable. Work also provides a means for individuals to develop friendships or satisfy social outlets that connects them more directly with the community. Work is said to contribute to self-esteem in which the individual fosters a sense of competence and mastery over both himself and his/her environment. Engaging in activities that produce something valued by other people also creates a sense of usefulness for the individual (Thornton \& Maynard, 1989).

Playwright Barbara Garson (1975) stated that work is a human need that follows just behind the need for food and the need for love. From her perspective, a human need combined with a means to a visualized outcome creates an energy that drives an individual to complete a task. She interviewed factory workers throughout the United States to investigate the meaning of routine work. She found that workers make a constant effort to put meaning and dignity back into their daily activity even if the job is made up of 
boring, monotonous tasks. She concluded that people passionately want to work.

Furthermore, psychologist Daniel Yankelovich (1981) conducted a study that associated four American cultural values with work. The "Good Provider" theme suggests that the person who provides for his/her family is a real man or woman. The "Independent" theme equates work with autonomy. The "Success" theme states that hard work leads to success. The "Self-respected" theme suggests that work, whether menial or exalted, has dignity. He concluded that a change in the American culture creates a change in the meaning of work, since the work ethic is embedded in the basic life values of our society.

Work as a Prescription for Therapy

The philosophy practiced during the Moral Treatment era of the 18th century emphasized respect for human individuality. The perceived need for individuals to engage in purposeful activity with other individuals was also indicated. These ideals became the foundation for occupational therapy practice (Bockoven, 1971). At this time, work as a prescription for therapy was assigned to inmates in mental institutions in the form of domestic chores, agricultural activities, and recreation as a means for enhancing morale and improving discipline among the inmates. As well, the concept of regularity and bodily 
action involved with work activities were considered therapeutic. In this context, work was not equated with potential employment in the community, but was considered a means for supporting the work ethic, fulfilling the needs of the inmates, and providing a tenuous, yet dignified connection to society (Harvey-Krefting, 1985).

In the mid-1800's, the therapeutic use of work largely disappeared due to a shift in the medical perspective which implied that mental illness was due to an incurable disease of the brain and no longer treatable with work activities. The once humanistic philosophy of the time now emphasized individualism and personal accountability of therapists for their prescriptions (Harvey-Krefting, 1985; Kester, 1983). It was not until the early 1900's that work as a therapeutic modality was again recognized with its new focus on the physically disabled population (Bockoven, 1971; HarveyKrefting, 1985).

\section{Work as Occupation}

The legacy of Moral Treatment and the concept emphasizing the therapeutic use of work was revitalized in response to the changing needs of society and the development of occupational therapy in the early 20 th century. During this time frame, the primary focus of occupational therapy treatment was on people with physical disabilities since they were viewed as being more treatable 
than the mentally ill population (Harvey-Krefting, 1985; Hopkins, 1983; Kester, 1983). The health-restoring effects of occupation, and a broader definition of work that referred to the intrinsic sense of productivity rather than paid employment was introduced and accepted by society (Harvey-Krefting, 1985). According to Kielhofner and Burke (1983), work remediated problems with idleness, poor habit formation, and a lack of social skills. Meyer (1977) further commented that the balance of productive and pleasurable occupations was essential to recovery and health.

This broad definition of work and respect for occupation became the forefront for vocational rehabilitation. Early occupational therapists were known as reconstruction aides and provided work to wounded soldiers after the first world war by means of assessing personal interests, skills, and abilities. This information was evaluated and used by the military hospitals to select an appropriate vocational training program (Robinson, 198I). These programs consisted of exercises, self-care, sheltered workshop tasks, and vocational training (Marshall, 1985). Individuals with severe and persistent mental illness were assigned crafts as prevocational work projects with the intent to increase motivation (Woodside, 1971). Prevocational work was considered a means for fostering intrinsic productivity and fulfillment rather than a goal 
for future employment in the labor market (Harvey-Krefting, 1985).

Work as Employment

In the early $1950^{\prime} \mathrm{s}$, a major change in the concept of work evolved in response to the development of the medical model of thinking. The once broader view of work that emphasized therapeutic use, intrinsic productivity, personal fulfillment, and the balance of occupations was now referred to as gainful employment which included specific job skills and remuneration. Consequently, the role of occupational therapists became more specialized with structured prevocational programs intended to develop work habits, work tolerance, and degrees of efficiency necessary for entry into vocational training programs. Cromwell (1966) suggested that occupational therapists take on a more objective and professional perspective toward work as work evaluators, program coordinators, and business managers rather than the traditional role of observers.

Furthermore, in response to the demands for evidence of effectiveness, studies were conducted to predict successful vocations (Ethridge, 1968) and patient outcomes with respect to varying rehabilitation programs (Bailey, 1968). Attention was focused on the theory behind the practice. Work was conceptualized in terms of contingency management, reinforcers for work behavior, and the needs-satisfaction 
principle. Crafts, as a therapeutic modality, were criticized by the occupational therapy profession and the general medical community. At that time, it was believed that crafts failed to provide patients with realistic challenges necessary for transitioning into community-based employment. Successful vocational rehabilitation was equated with returning the patient to work; work became synonymous with employment.

\section{Work as Productive Activity}

Changes in the health care system were prompted by the general dissatisfaction with the medical model philosophy, the trend toward preventative health measures, and increases in the number of individuals with severe and persistent mental illness. With this change, the meaning of work was once again evaluated with consideration for the American work ethic and the new federal labor laws (Lamb \& Edelson, 1976). Kielhofner (1983), taking a more generalist approach to vocational rehabilitation, defined work as any form of productive activity, regardless of reimbursement. Work was thought to be the basis for human performance or occupation which provided a sense of productivity, mastery, and competence for the individual. The definition of work reflecting the intrinsic sense of productivity and work as a means to an end was revitalized. Furthermore, in 1994, work was addressed by the American Occupational Therapy 
Association in the third edition of Uniform Terminology for Occupational Therapy (1994). Work was now referred to as work and productive activities and defined as purposeful activities necessary for self-development, social contribution, and Iivelihood.

Work For Adults with

Severe And Persistent Mental Illness

The philosophical beliefs about people and about work have clear implications for the way we structure and deliver rehabilitation services. The legislative history of vocational interventions illustrates how these changing beliefs have been translated into new programs and new service models. The value of work, the current labor market, and the legislation pertaining to work for individuals with severe and persistent mental illness are discussed.

\section{The Value of Work}

The meaning and value of work for individuals with severe and persistent mental iliness echoes that which is held by other members of society. Individuals have an intrinsic desire to be productive members of society and to contribute to the community in a personally meaningful way (Hagedorn, 1992). Productive work in the hospitals was believed to promote personal identity, increase self-worth, and provide a means for maintaining self-respect. Ethridge (I963) stated that health and personal well-being are 
fostered by the gratification of accomplishment and dignity associated with work.

The philosophy of occupational therapy proffers the concept of occupation, including work as a means for purposeful, productive activity. Work can be defined broadly as any paid or nonpaid productive activity that enhances personal satisfaction, stimulates the intrinsic sense of value, and contributes to society. According to Fidler (1966), the desire for an individual to feel like a contributing member of society is integral with man's basic human needs. Other human needs conceptualized by Fidler (1966) were as follows: 1) the need for identity, 2) the need for relatedness, and 3) the need for consensual validation. Each of these needs are related to the idea of work as a catalyst for productivity and independence since employment can be related to self-concept and can aid in the development of personal identity. Hence, employment for persons with disabilities can potentially satisfy the need to perceive oneself as a contributing member of society and, in turn enhance quality of life.

\section{Current Labor Market}

In the United States, there are approximately 1.7 to 2.4 million adults in the United States with severe and persistent mental illness (Goldman, Gattozzi, \& Taube, 1981). Due to the nature of the disorder, severe and 
persistent mental illness implies significant impairment resulting in long-term, expensive treatment. Torrey (1988) projected that the long-term treatment costs for persons with severe and persistent mental illness will reach 155 billion dollars by the year 2007. Kaplan and Sadock (1981) suggest that much of the cost results from the limited involvement of this population in gainful employment.

The first nationwide survey of people with disabilities in 1986 revealed the importance that people with disabilities place on employment with respect to contributing to society as a productive member and decreasing expenditures for public benefits (Louis Harris \& Associates, 1986). A Harris poll indicated that two thirds of all disabled American adults were unemployed due to the lack of opportunity for employment rather than the lack of desire or ambition for engaging in work (Louis Harris \& Associates, 1986). The rehabilitation success rate for individuals with psychiatric disorders is lower than the success rate for any other disability (McCue \& Katz-Garris, 1983). More specifically, according to Anthony and Blanch (1987), individuals with severe psychiatric disorders represented 15 percent or less of the competitively employed population.

Between 1977 and 1984, the national competitive employment rates did not improve for individuals with severe 
and persistent mental illness utilizing vocational

rehabilitation services (Andrew, Barker, Pittman, Mars, Straining \& Larks, 1992). Furthermore, rehabilitation programs have been significantly less effective in serving persons with psychiatric disabilities as compared to those with physical disabilities (Andrew et al., 1992; Anthony, 1982; McCue \& Katz-Garris, 1983; Skelley, 1980). According to Patti and Morrison (1982), clients with mental illness are more difficult to place and require more intensive follow-up to sustain employment than do clients with other types of disabilities. Difficulties encountered from the varying manifestations of severe psychiatric diagnoses may interfere with the performance of life tasks including work, play, and self-care.

Thornton and Maynard (1989) suggest that there are varying factors that influence an individuals' ability to sustain and maintain employment, including general unemployment conditions, issues with employers, and work disincentives created by income-support programs. The general level of unemployment in the economy influences job maintenance for disabled persons. When an excess supply of labor exists, these persons are at a particular disadvantage in the labor market. As well, discriminatory practices or misperceptions about the capabilities of individuals with severe and persistent mental illness causes many employers 
to refrain from hiring these persons.

Another factor that induces a low-level of job-holding among disabled workers is the disincentives created by the income-support programs such as SSDI and SSI. Specifically, the termination of benefits to persons who, because of their employment, are no longer strictly considered to be disabled causes problems. Even if their earnings were not at a level that would cause a termination in benefits, disincentives still exist. Income-support programs generally reduce payments as earnings increase, so persons may be reluctant to work in fear of losing these benefits. However, many employment programs have successfully enrolled and placed persons who receive benefits from income-support programs. This suggests that some benefit recipients are motivated to work, and that some employment programs can increase earnings for clients by an amount that would not cause them to lose needed assistance. Recent social security legislation has attempted to reduce the financial disincentives stemming from SSDI and SSI (Thornton \& Maynard, 1989).

Legislation Pertaining To Work

Varying legislative attempts have been made to enhance the employment opportunities for individuals with severe psychiatric disabilities. In the mid-1920's, individuals with severe and persistent mental illness were excluded from 
the vocational rehabilitation legislation due to a governing belief that mental illness was a disease of the brain and thereby untreatable. In 1954, however, the laws changed when amendments to the Vocational Rehabilitation Act was passed, providing funds to nonprofit sheltered workshops. These funds were to be used to develop programs that would prepare disabled workers, both physically and psychiatrically challenged, for community-based employment. This marked the beginning of a period of extensive research and the development of prevocational and vocational programs for adults with severe and persistent mental illness.

The Vocational Education Act and provisions of the Comprehensive Employment and Training Act (1973) and the Job Training Partnership Act (1982) encouraged the participation of disabled persons in vocational training and employment programs. It was believed that individuals diagnosed with severe and persistent mental illness could be encouraged and helped to reach their optimal potential for employment through vocational training and structured work programs. The Revenue Act of 1978 provided tax credits for employers willing to hire individuals with disabilities. Amendments to the Social security Act in 1980 and 1984, attempted to reduce some of the work disincentives to disabled Americans that are created by the Social security Disability Insurance (SSDI) and the Supplemental Security Income (SSI) programs. 
These laws and the programs they have inspired have greatly enhanced the employment prospects for persons with severe psychiatric disabilities.

On July 26, 1990, the Americans with Disabilities Act (ADA) became a law (Public Law 101-336). Justin Dart, Chair of the President's Committee on Employment of People With Disabilities, indicated that the ADA would provide persons with disabilities with an opportunity to participate as equal members of society (Dart, 1990). Many advocates of the law suggest that the specific provision for employment addressed under Title I may be most significant, since competitive employment contributes to the economic market and promotes independence among its members. Since work illuminates the highest degree of human function as well as lies at the heart of the American creed, efforts to engage and increase the rate of employment for individuals with severe and persistent mental illness should be viewed positively and will directly support the Title I provision issued under the ADA of 1990 (Public Law 101-336).

Although the above legislative attempts increased potential employment opportunities for persons with disabilities, a number of these individuals remain unemployed. The problems in placing and sustaining adults with severe and persistent mental illness in community-based employment extend beyond the hospitals to the business 
community. In response to this prevailing employment problem, further efforts have been undertaken to refine public policy. Specifically, the transitional employment and supported employment program models were developed to provide a more direct approach for enhancing work prospects for this population. Both programs involve jobs in which the worker produces goods and services that have economic value, in which the worker receives a wage, and in which the worker has an opportunity to interact with nondisabled peers. Origins of the Transitional Employment Program Model

Although individuals with mental illness had been eligible under the law for Vocational Rehabilitation services since 1943, people with severe psychiatric disabilities were not well served with respect to treatment since programs serving this population were not well defined (Skelley, 1980). The Transitional Employment Program (TEP) was developed at Fountain House in 1958, for individuals with severe and persistent mental illness as a link between the sheltered workshop environment and community-based employment. The TEP provides limited-duration services oriented toward placing and training persons in communitybased jobs and establishes contracts with businesses in the community to reserve entry-level, part-time positions.

Initial interviewing, on-the-job training, and support services are available for the clients and represents a 
bridge for persons transitioning back into the community work force. On-the-job training involves aiding the participants in performing the specific functions of the job. At least part of the training is typically provided on the job, which is particularly helpful for individuals with severe and persistent mental illness who experience difficulties in generalizing newly acquired skills to different settings. Support services may be provided to help clients cope with a new work supervisor, deal with coworkers, adapt to new job tasks, and adjust to working again. On the other hand, the employers are offered a potentially never-ending supply of labor, work coverage in case of emergencies such as illness, and possible training assistance for supervisors and other employees in working with individuals with disabilities. Dulay and steichen (1983), reviewed the market for transitional employment and identified opportunities for employment involving unskilled, entry-level positions in the janitorial, food service, and clerical fields. In addition, the Fountain House Annual Report for 1980, quoted a national listing of TEP employers offering approximately 911 TEP placements with the potential for an upwards of 137 new jobs annually. Origins of the Supported Employment Program Model

Supported Employment (SE) has its origins in the early $1980^{\prime} \mathrm{s}$, when it was reported that approximately 90,000 
students with developmental disabilities were graduating from public schools and transitioning into the community without extended services or appropriate job opportunities (Dept. HHS, 1984). The Developmental Disabilities Act of 1984 (P. L. 98-527), provided a mandate for addressing employment-related activities such as SE which included the four basic components: job placement, job site training, ongoing monitoring, and follow-up (Wehman \& Kregal, 1985).

Specifically, SE for persons with severe and persistent mental illness originated from a lack of access to vocational rehabilitation services rather than from difficulties transitioning from a mandated program like special education into the community. SE provides on-going, follow-along services to enable individuals to remain employed for extended durations.

The National Institute of Mental Health (NIMH) Community Support Program created a new perspective for individuals with severe and persistent mental illness with respect to employment. The organization of services and supports necessary for these individuals to live productively in the community was addressed. The Rehabilitation Services Administration (RSA) signed a collaborative agreement with the National Institute of Mental Health in 1978, and funded two Rehabilitation Research and Training Centers focused on psychiatric 
disabilities. This agreement led to an interagency cooperative agreement in 1980 between the NIMH, the RSA, the National Institute on Handicapped Research, and the Council of State Administrators of Vocational Rehabilitation which advocated for improved and more comprehensive services for individuals with severe and persistent mental illness (Anthony \& Blanch, 1987). Eventually, persons with severe psychiatric disabilities were acknowledged in the Rehabilitation Act of 1973 (P. I. 99-506). As well, the concept of employability was refined to include part-time work. Emphasis for the need for more functional assessments and a separate grant program for TEP and SE was also indicated. Essentially, SE helps individuals with severe and persistent mental illness to choose, attain, and sustain paid employment in integrated work settings by means of providing these persons with the needed job development, placement, training, and support so that they can experience the economic and psychological benefits of working. SE is another vocational rehabilitation option that intends to increase the number of individuals with severe and persistent mental illness in the community-based labor market. The SE approach may represent a potentially viable approach to improving vocational outcomes for individuals with severe and persistent mental illness (Anthony \& Blanch, 1987; Bond, 1987). 


\section{Conceptual Framework}

Specific occupational therapy models and frames of reference which have been utilized in prevocational and vocational rehabilitation programs include the following: humanistic, occupational performance, behavioral, occupational behavior, human occupation, role acquisition.

The Humanistic frame of reference refers to a philosophy or attitude toward treatment (Hagedorn, 1992) and is considered to be the earliest model on which occupational therapy practice is based (Reed, 1984). In this model, learning is seen as a continuous search for autonomy, growth, and personal fulfillment. Humanism emphasizes the client-centered approach to treatment which encourages each individual to direct the rehabilitation process and to select and prioritize personal goals. In other words, the client is given the opportunity to control his/her own life and direct his/her own therapy. Personal responsibility and decision-making are essential components of the Humanist framework (Hagedorn, 1992). In prevocational and vocational rehabilitation for individuals with severe and persistent mental illness, the relevance of this framework is implicit in the value placed on independence, personal choice, and self-actualization. A humanistic attitude encourages the client to direct the rehabilitation process and to select and prioritize personal goals. 
Reed and Saunderson (1983) note that the American occupational therapy association recognizes the Occupational performance Model as the official practice model of the Occupational Therapy discipline. The Occupational Performance frame of reference examines functional performance in the areas of work, play/leisure, education, and self-care. Health is defined in terms of functional role performance with respect to the maintained balance between the areas of occupational performance. Deficits in occupational roles are related to the inefficient integration of the occupational performance component subsystems. Purposeful and enabling activities serve as a means for remediation of deficits in the occupational performance areas (Hagedorn, 1992). Although all performance areas are addressed in prevocational and vocational rehabilitation for individuals with severe and persistent mental illness, the primary focus is in the area of work. Remediation of poorly developed work habits and skills is emphasized. This model is also significant in prevocational and vocational rehabilitation due to the respect and value placed upon the concept of productive occupations (Reed, 1984). Occupation, in general, refers to the goal-directed use of time, energy, and interest. Productive occupations are identified by Reed (1984) to include the following: work, play, volunteerism, student amateurism, prevocation, 
vocation, homemaker, home management, and vocation activities. The American Occupational Therapy Association further identified work and productive activities to include home management, care of others, educational activities, and vocational activities (AOTA, 1994).

The behavioral frame of reference suggests that behavior, which is both learned and controllable determines the ability for an individual to function in activities of daily living, work, and leisure. From this viewpoint, learning is the basis of all behavior and may generate a more effective behavior known as adaptive behavior or maladaptive behavior. As well, it is proposed that behavior can be reinforced or extinguished using interventions that are aimed at reinforcing adaptive behavior or correcting maladaptive behavior. Specific treatment techniques such as operant conditioning, reciprocal inhibition, desensitization (Tiffany, 1983), shaping, chaining, generalization and extinction (Reed, 1984) are described. An individual acquires and maintains health and stability when given the opportunity to control his/her own behavior. In prevocational and vocational rehabilitation, the patient is actively engaged in a learning process utilizing activities, workshops, and transitional work experience to facilitate the development of the behaviors necessary for functioning in a particular work environment. 
The Occupational Behavior frame of reference examines the functional performance of occupational roles by addressing the developmental continuum of play and work (Hagedorn, 1992). Occupational roles are defined as activities that engage a person's time on a regular basis (Hagedorn, 1992) such as preschooler, adolescent, student, worker, and retiree. Each role in the developmental sequence involves the proper translation of skills and habits that must be acquired for successful progression to future roles. Failure to build the necessary skills and habits at an earlier stage of occupation results in occupational role dysfunction. Treatment is structured to provide normal developmental opportunities that will remediate deficits in occupational behavior by fostering habit and skill acquisition. Work is the major activity in adulthood and refers to any productive activity, paid or unpaid, which is done for oneself, one's family, or society.

Human occupation utilizes a systems approach for treatment. The individual is described as an open system that is continuously exploring, changing and interacting with the environment. This model assumes that the occupational areas of work, education, play/leisure, and self-care are critical to daily experiences which aid in satisfying the intrinsic need to master the environment. Intervention is directed toward assessing and remediating 
deficits within three subsystems of the individual (Kielhofner \& Burke, 1980). The volitional subsystem is composed of personal causation, values, and interests. The habituation subsystem includes one's values and habits. The performance subsystem includes skills and abilities. Integration of the subsystems facilitate occupational behavior which is essential to adequate performance of daily occupations. With respect to the occupation of work, prevocational and vocational rehabilitation provides the individual with the opportunity to gain skills, develop habits and roles, and explore personal effectiveness, values and interests.

The Occupational Role Acquisition frame of reference addresses a dynamic process that enables an individual to assume the demands of societal roles such as preschooler, student, worker, and retiree. Role skills needed for the formation of habits are learned and developed in activities of daily living, work, social interaction, leisure, and play (Christianson \& Baum, 1991). These role skills integrate to form habit structures that direct behavior necessary for the adequate fulfillment and acquisition of occupational roles. According to Heard (1977), an occupational role determines the direction of daily activities, the allocation of time, the contribution to society, and personal self-worth.

Prevocational and vocational rehabilitation primarily 
focus on the acquisition of the worker role. An individual with severe and persistent mental illness may have difficulty acquiring and transitioning between occupational roles due to the nature of the disability and problems with successfully mastering prior roles necessary for the acquisition of new roles. Intervention emphasizes the promotion of self-esteem and identity, cognitive development, dyadic and group interactions, learning and modeling (Hagedorn, 1992). Acquisition of the worker role is facilitated when an individual has the opportunity to learn the behaviors expectant from the role in a simulated work environment. The individual must be given the opportunity to develop work habits by experiencing all aspects of the job including jobs tasks, coworkers relations, supervision, time demands, and potential job constraints.

\section{Summary}

This literature review presented research on community mental health, prevocational and vocational rehabilitation, occupational therapy, and the current labor market for individuals with severe and persistent mental illness. The literature was organized into three subheadings: the meaning of work, work for adults with severe and persistent mental illness, and conceptual framework.

The meaning of work was appraised with respect for its variations in definition and significance in society. Work 
was addressed as an integral part of the American culture, as a prescription for therapy, as an occupation, as employment, and as productive activity.

The value of work for individuals with severe and persistent mental illness was addressed in reference to the philosophy of occupational therapy and Fidler's (1966) description of work as integral with man's basic human needs. The review of the current labor market revealed the importance that people with disabilities place on employment and addressed employment rates and vocational rehabilitation programs. Legislation pertaining to work for individuals with psychiatric disabilities, transitional employment programs, and the supported employment approach to rehabilitation were also discussed.

Occupational therapy models and frames of reference which have been utilized in prevocational and vocational rehabilitation programs were specified in the literature review. The models and frames of reference addressed were listed in order of appearance: Humanistic, Occupational Performance, Behavioral, Occupational Behavior, Model of Human Occupation, and Occupational Role Acquisition. 
CHAPTER 3

PROCEDURES AND METHODOLOGY

Purpose

The purpose of the study was to examine employment outcomes for individuals with severe and persistent mental illness six months prior to utilizing vocational rehabilitation services delivered by CVE/Keystone and three, six, and nine months after starting the program.

Research Design

This study used a chart review methodology to gather

data for examination. Authorized access to the client charts at CVE/Keystone was obtained with written permission from the Program Director of Keystone, Glenda Jeong, MA, OTR and the Program Director of CVE, Fran Gomory. The data was analyzed using description and inferential analysis.

Research Questions

The research was designed to answer the following questions :

1. Is there a change in the number of clients employed six months prior to utilizing service at CVE/Keystone and three, six, and nine months after starting the vocational rehabilitation program?

2. Is there a change in the rate of employment as measured by the number of work hours per week six months prior to utilizing service at CVE/Keystone and three, six and nine 
months after starting the vocational rehabilitation program? 3. Is there a change in the longevity of employment as measured by the duration of time job maintained after vocational rehabilitation delivered by CVE/Keystone is utilized?

4. Is there a change in the wages earned six months prior to utilizing service at CVE/Keystone and three, six, and nine months after starting the vocational rehabilitation program? 5. Is there a change in the distribution of social security benefits six months prior to utilizing service at $\mathrm{CVE} /$ Keystone and three, six, and nine months after starting the vocational rehabilitation program?

$$
\text { Description of the setting }
$$

CVE/Keystone is a partnership that provides a SE environment combined with a TEP in which consumers are given the opportunity to make independent choices regarding vocational pursuits that will increase potential for successful and competitive, community-based employment. Keystone Vocational Services (Keystone), established in 1989, is a county funded vocational rehabilitation center located in San Francisco. Keystone is dedicated to integrating qualified individuals with psychiatric disabilities back into the community work force. Keystone works in a partnership with Community Vocational Enterprises (CVE), a small nonprofit division of the San Francisco study 
Center. CVE establishes and operates varying businesses which include the following: janitorial, catering/food service, cafe, messenger/driver, and clerical work. These businesses provide paid transitional employment for mental health consumers with consideration for varying skill levels and work experience.

CVE/Keystone offers workshops on job seeking skills and SSI/SSDI benefits, as well as provides functional assessments by an occupational therapist, vocational and educational counseling, referral and coordination services. An Adolescent Program and Client Resource Center are also available at CVE/Keystone. CVE/Keystone assists consumers of mental health services to identify individual strengths and achieve maximum vocational potential. The agency provides SE and an environment in which clients are given the opportunity to identify personal interests, explore work readiness, set realistic goals, develop vocational skills and habits, increase endurance, gain self-confidence, make independent choices, as well as obtain and maintain employment that matches personal interests and abilities.

Employment specialists match the interests and abilities of the clients with the needs of the employer. Continued services are offered to workers and their employers as long as needed to maintain employment. SE services include the following: vocational planning, peer 
employment counseling, occupational therapy assessments, job development and placement assistance, job seeking skills training, educational workshops, work experience, referral to community educational/training resources, job coaching to maintain employment, reasonable accommodations, an employee assistance program, a resource center for independent job searching, and long-term follow-along services.

CVE/Keystone can offer an employer fully qualified, dependable employees, free job training by employment specialists and job coaches, on-going support for the employer and employee which is a no fee service, assistance in developing reasonable accommodations for both disabled and non-disabled staff, and assistance in obtaining an annual tax credit of up to $\$ 6,000.00$.

subjects

The subjects for this study consisted of individuals with severe and persistent mental illness who utilized vocational rehabilitation services from CVE/Keystone. The CVE/Keystone agency serves individuals 16 years of age and older who have been diagnosed with a severe and persistent mental illness, who live in San Francisco, and who are currently affiliated with a San Francisco Mental Health Provider. The subjects of this study had a work goal of at least 4 hours per week and were therefore eligible to work with the San Francisco Department of Rehabilitation. Also, 
the subjects had attended a CVE/Keystone Open Orientation and Intake Interview between the months of May and october 1994 .

The sample was obtained using the official CVE/Keystone Open Orientation Sign-in Sheet. At CVE/Keystone, an individual who is interested in utilizing vocational rehabilitation services and meets the CVE/Keystone basic requirements is given the opportunity to sign-up for the official Open Orientation meeting. The Intake Coordinator uses the sign-in sheet to document attendance at the Open Orientation meeting. This sign-in sheet is also used to schedule Intake Interviews with the CVE/Keystone Intake staff. The sign-in sheet is dated and officially stored in the Client Resource Manual located in the office of the Intake Coordinator. In this manual, it is also noted if the client is eligible to work for the Department of Rehabilitation. The researcher used the information provided in this manual to identify a non-random sample of convenience consisting of the first 30-50 individuals who met the above criteria. A list of 37 individuals who met the designated criteria were identified and selected as the subject sample for this study.

Data Collection Instrument

In order for the researcher to develop an instrument for data collection that provided relevant and reliable 
information regarding the research questions for this study, the Delbecq nominal group process was utilized. Delbecq and Van de Ven (1975) state, "Before quantitative research measures can be developed for data collection, a qualitative understanding of the major parameters of the problem area needs to be understood; otherwise the collected data may be invalid" (p.337). Hence, another reason for utilizing the nominal group process technique was to provide content validity to the data collection tool.

Five expert individuals in the mental health field were asked to participate in the nominal group process. The meeting provided the researcher with the opportunity to brainstorm ideas with expert staff in order to formulate appropriate and relevant questions for the instrument. The group provided the researcher with information pertaining to the CVE/Keystone charting system, so that the researcher's time was used efficiently during data collection. As well, a discussion pertaining to the self-reported work history located in the chart was initiated to generate more information relevant to the formulation of the document. To explain, all clients complete the CVE/Keystone work history sheet. This form is completed in the presence of the Intake Coordinator who facilitates the process and asks in depth questions as to the nature of the previous work experience including hours worked, wages earned, supervision, and 
Social security benefits. The researcher intended to gain additional informational as to the types of information available in a standard CVE/Keystone chart. A sample instrument (Appendix A) was created by the researcher as a possible guideline for the group meeting.

It was determined during the nominal group process that information regarding the specific location of employment after starting the program was insignificant to the study and therefore should be dismissed. As well, it was suggested that the exact amount of social security benefits be disregarded from the study since the availability of that information was inconsistently recorded in the CVE/Keystone charts. Instead, the group suggested that the researcher focus on the number of individuals utilizing government assistance in the form of social security benefits. The group also recommended that age and sex be added to the data collection tool for additional demographic information. The sample data collection tool (Appendix A) was revised and. enhanced to incorporate the suggestions generated during the nominal group process.

The final data collection tool used in this study (Appendix B) was divided into five basic sections. The first section noted the month in which the subject completed the Open Orientation and Intake Interview. Although the researcher knew that all of the subjects completed the 
designated subject criteria within the months of May and October 1994, it was necessary to know the exact month so that the data regarding the research questions could be assessed accurately along the incremented time line. In this section, age and sex were also indicated. The last four sections of the data collection tool were identical with respect to the questions asked, but were differentiated by a designated time frame (i.e. 6 Months Prior, 3 Months After....). The five questions asked for data regarding employment status, the number of work hours per week, the wages earned, and distribution and utilization of Social Security Benefits. The information gathered from the client charts were anonymous, since no individual subject identification was included on the data collection tool. 
CHAPTER 4

DATA ANALYSIS AND RESULTS

Population

A population of individuals utilizing vocational rehabilitation services from CVE/Keystone was used for this study. The CVE/Keystone agency serves individuals 16 years of age and older who have been diagnosed with a severe and persistent mental illness, who live in San Francisco, and who are currently affiliated with a San Francisco Mental Health Provider. From the general population of clients utilizing services at CVE/Keystone, a sample group of 37 subjects was selected for chart review. The 37 subjects were eligible to work with the Department of Rehabilitation and had attended both an open Orientation meeting and an Intake Interview at CVE/Keystone between the months of May and October 1994 .

Among the $37(100 \%)$ subjects, $16(43 \%)$ were female and 21 (57\%) were male. The age of the subjects ranged from 1659 with an average age of 39 years for the total group, 45 years for the female subjects and 34 years for the male subjects.

\section{Results}

The variables studied in this research included the following multiple measures: number of subjects employed, rate of employment, Iongevity of employment, amount of wage 
earned, and variations in the distribution of social

Security benefits. In this section, the data pertaining to the five research questions will be discussed.

Question 1: Is there a change in the number of clients employed six months prior to utilizing service at CVE/Keystone and three, six, and nine months after starting the vocational rehabilitation program?

Among the 37 subjects, three $(8 \%)$ of the subjects were employed in the community prior to utilizing vocational rehabilitation services at CVE/Keystone and 34 (92\%) were unemployed. Three months after utilizing service, 7 (19\%) of the 37 subjects were employed and $30(81 \%)$ subjects remained unemployed. Six months after starting vocational rehabilitation, $16(43 \%)$ of the subjects were employed and 21 (57\%) remained unemployed. Nine months after starting CVE/Keystone, $26(70 \%)$ of the 37 subjects were employed and $11(30 \%)$ subjects remained unemployed. The data summarizing the changes in the amount of subjects employed before and after starting vocational rehabilitation at CVE/Keystone were arranged in Table $1 \mathrm{~A}$.

Some of the subjects utilizing service at CVE/Keystone participate in the volunteer CVE/Keystone clerical program to relearn skills from past experience or to gain new skills for future pursuits. These subjects were considered unemployed in the above data. Only subjects receiving a wage 
were included in the employed data. These subjects were distinguished for further clarification in Table 1B, providing the actual breakdown of those individuals employed and unemployed and those working without monetary compensation in the volunteer program.

In Table IB, the data for the employed subjects remained the same as in Table $1 \mathrm{~A}$. The data describing the unemployed subjects, however, differ in the number of subjects unemployed. Six months prior to utilizing service at CVE/Keystone there were 34 (92\%) subjects unemployed. Three months after starting the program, 22 (59\%) subjects were unemployed and $8(22 \%)$ were working in the volunteer clerical program. Six months after starting CVE/Keystone, 14 $(38 \%)$ subjects were unemployed and 7 (19\%) of the subjects were participating in the volunteer clerical program. Nine months after utilizing service, 10 (27\%) subjects were unemployed and $1(3 \%)$ subject was working in the CVE/Keystone volunteer clerical program.

Question 2: Is there a change in the rate of employment as measured by the number of work hours per week six months prior to utilizing service at CVE/Keystone and three, six, and nine months after starting the vocational rehabilitation program?

The rate of employment as measured by the number of work hours employed each week was examined for each subject 
Table 1.A

Number of Subjects Employed

$\mathrm{N}=37$

Status 6 Mos Prior 3 Mos After 6 Mos After 9 Mos After

\begin{tabular}{lllll}
\hline$E$ & 3 & 7 & 16 & 26 \\
\hline$U$ & 34 & 30 & 21 & 11 \\
\hline
\end{tabular}

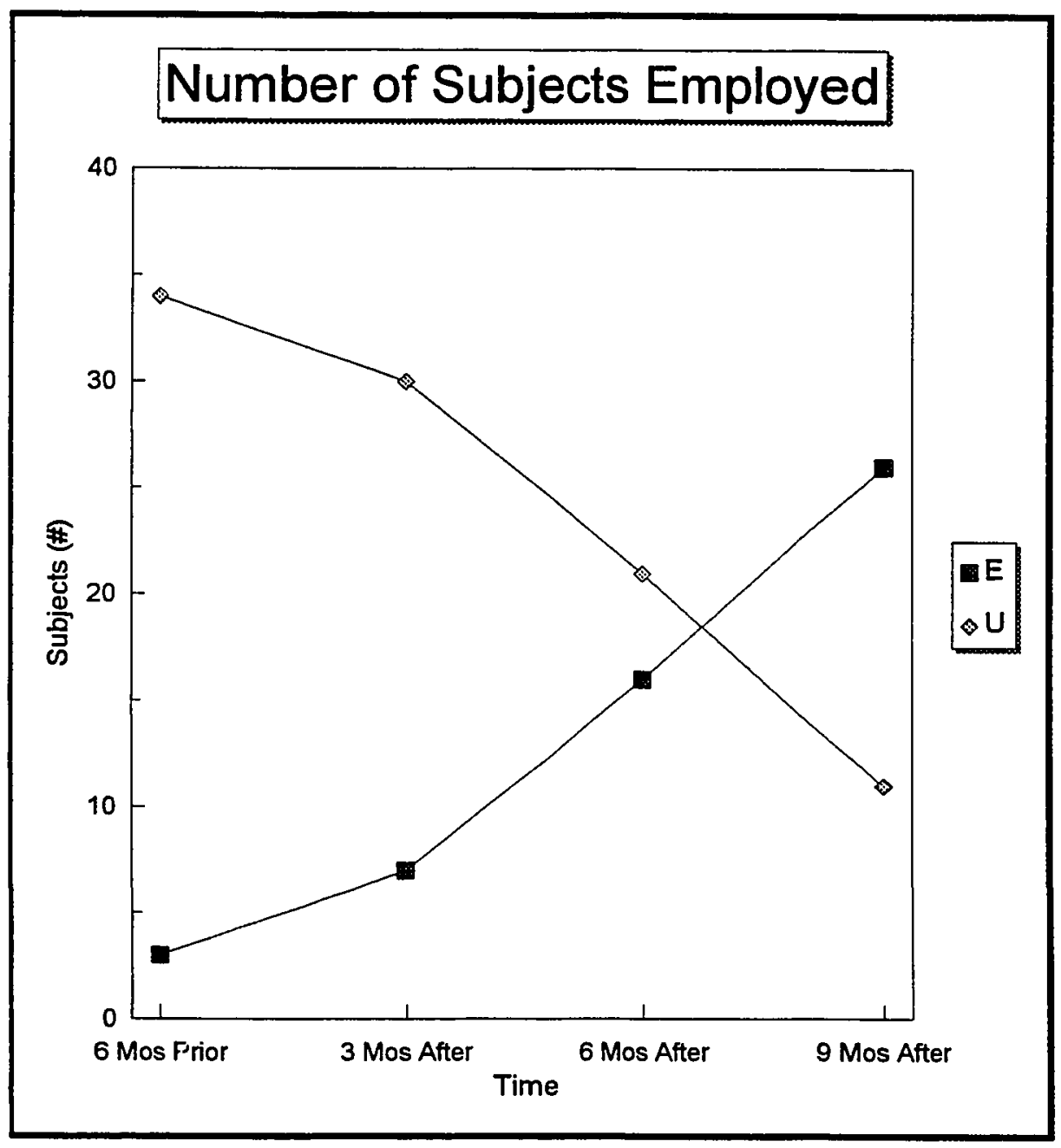


Table 1.B

Number of Subjects Employed

$\mathrm{N}=37$

Status 6 Mos Prior 3 Mos After 6 Mos After 9 Mos After

\begin{tabular}{ccccc}
\hline $\mathrm{E}$ & 3 & 7 & 16 & 26 \\
\hline $\mathrm{U}$ & 34 & 22 & 14 & 10 \\
\hline $\mathrm{V}$ & 0 & 8 & 7 & 1 \\
\hline * E=employed; & $\mathrm{U}=$ unemployed; & V=volunteer
\end{tabular}

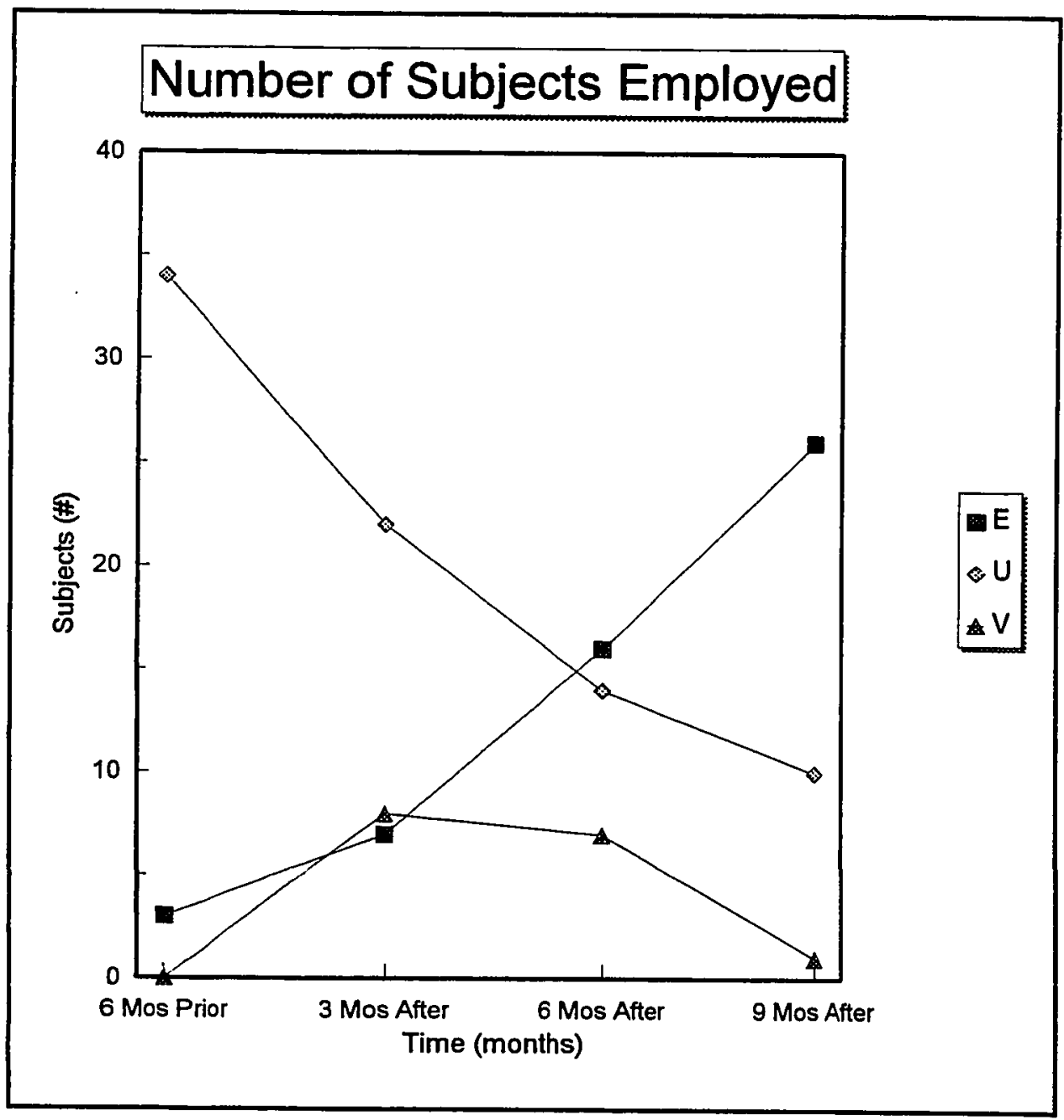


six months prior to starting the CVE/Keystone program and three, six, and nine months after utilizing service. Those components are arranged according to the number of work hours per week over time in Table 2 (N=37).

Six months prior to starting vocational rehabilitation at CVE/Keystone, 1 subject (3\%) was working 6-10 hours per week; 1 subject (3\%) was working 16-20 hours per week; 1 subject $(3 \%)$ was working 21-25 hours per week. The remaining 34 ( $91 \%)$ subjects were unemployed. An average of 1.3 work hours per week was tabulated for the sample population $(N=37)$. Three months after starting the program, 5 (14\%) subjects were working 1-5 hours per week; 1 (3\%) subject was working 6-10 hours per week; I (3\%) subject was working 1620 hours per week. Eight $(22 \%)$ of the subjects were participating in the CVE/Keystone volunteer clerical program. The remaining 22 (59\%) subjects were unemployed. An average of 1.8 hours per week was calculated for the subjects.

The following data were gathered regarding the number of work hours per week six months after utilizing vocational rehabilitation. Five (14\%) subjects working 1-5 hours per week, 5 (14\%) subjects working 6-10 hours per week, 1 (3\%) subject working 11-15 hours per week, 2 (5\%) subjects working 16-20 hours per week, 1 (3\%) subject working 21-25 hours per week, and 2 (5\%) subjects working 36-40 hours per 
Table 2

Rate of Employment

$\mathrm{N}=37$

Hours/Week 6Mos Prior 3Mos After 6Mos After 9Mos After

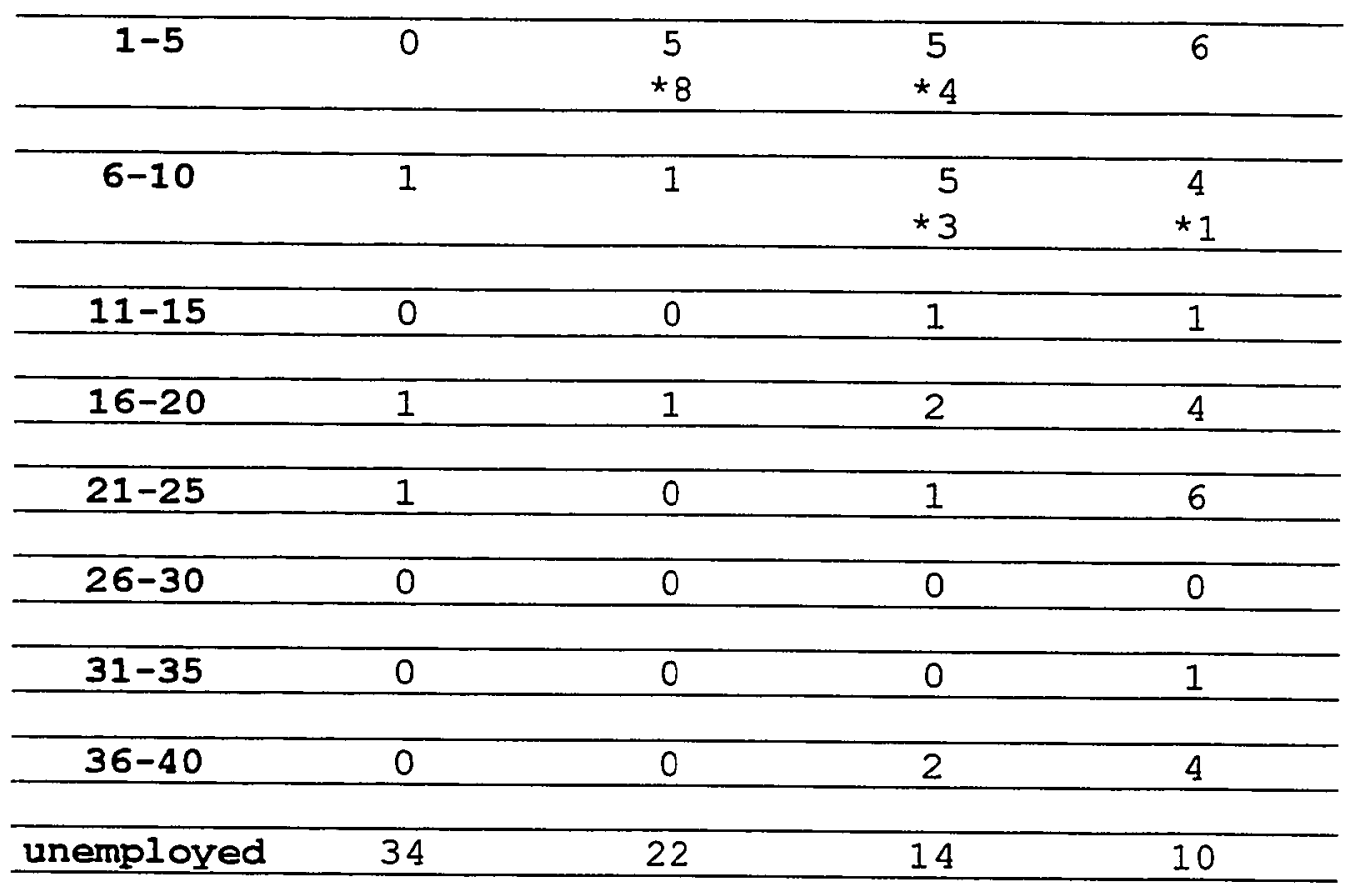

\begin{tabular}{lllll}
\hline Ave.\#hrs/wk $1.3 \mathrm{hrs} / \mathrm{wk}$ & $1.8 \mathrm{hrs} / \mathrm{wk}$ & $6.5 \mathrm{hrs} / \mathrm{wk}$ & $12.6 \mathrm{hrs} / \mathrm{wk}$ \\
\hline
\end{tabular}

* participant in CVE/KVS clerical volunteer program 
week. At this time, 7 (19\%) subjects were participating in the CVE/Keystone volunteer clerical program. Fourteen (38\%) subjects remained unemployed. An average of 6.5 hours per week was calculated for the subjects six months after starting the program. Nine months after utilizing service at CVE/Keystone, 10 (27\%) subjects remained unemployed. Six (16\%) subjects were working $1-5$ hours per week; 4 (11\%) subjects were working 6-10 hours per week; 1 (3\%) subject was working 11-15 hours per week; 4 (11\%) subjects were working 16-20 hours per week; 6 (16\%) subjects were working 21-25 hours per week; 1 (3\%) subject was working 31-35 hours per week; 4 (11\%) subjects were working 36-40 hours per week. One $(3 \%)$ subject was working in the CVE/Keystone volunteer clerical program. After nine months of utilizing service at CVE/Keystone, the average number of work hours per week was tabulated as 12.6 work hours per week. Question 3: Is there a change in the longevity of employment as measured by the duration of time job maintained after vocational rehabilitation delivered by CVE/Keystone is utilized?

Components for these data were arranged in Table 3 . Six months prior to utilizing vocational rehabilitation at CVE/Keystone, $3(8 \%)$ of the 37 (100\%) subjects maintained employment for at least six months. Of those three individuals, subject I maintained employment for at least 
Table 3

Longevity of Subjects Employed $\mathrm{N}=37$

\begin{tabular}{|c|c|c|c|c|}
\hline Subjects & 6Mos Prior & 3Mos After & 6Mos After & 9Mos After \\
\hline 1 & $E$ & $E$ & $E$ & $\mathrm{E}$ \\
\hline 2 & $E$ & $\mathrm{~V}$ & $E$ & $\mathrm{E}$ \\
\hline 3 & $E$ & $\mathrm{~V}$ & $\mathrm{~V}$ & $\mathrm{E}$ \\
\hline 4 & $\mathrm{U}$ & $\mathrm{U}$ & $\mathrm{V}$ & $\mathrm{V}$ \\
\hline $5-9$ & $\mathrm{U}$ & $\mathrm{V}$ & $\mathrm{V}$ & $\mathrm{E}$ \\
\hline 10 & $\mathrm{U}$ & $\mathrm{V}$ & $E$ & $E$ \\
\hline $11-14$ & $\mathrm{U}$ & $\mathrm{U}$ & $\mathrm{U}$ & $E$ \\
\hline $15-21$ & $\mathrm{U}$ & $\mathrm{U}$ & $\mathrm{E}$ & $E$ \\
\hline $22-27$ & $\mathrm{U}$ & $E$ & $E$ & $\mathrm{E}$ \\
\hline $28-37$ & $\mathrm{U}$ & $\mathrm{U}$ & $\mathrm{U}$ & $\mathrm{U}$ \\
\hline Totals & $3 E$ & $7 \mathrm{E}$ & $16 \mathrm{E}$ & $26 \mathrm{E}$ \\
\hline & $0 \mathrm{~V}$ & $8 \mathrm{~V}$ & $7 \mathrm{~V}$ & $1 \mathrm{~V}$ \\
\hline & $34 \mathrm{U}$ & $22 U$ & $14 \mathrm{U}$ & $10 \mathrm{U}$ \\
\hline
\end{tabular}


nine months or the duration of the study. Subject 2 also resigned from her current position to enter the CVE/Keystone volunteer clerical program. This particular subject was able to relearn past skills within a three month time frame and proceeded to maintain employment for at least six months or the remaining duration of the study. The last of those three subjects, Subject 3, also resigned from her current employment to enter the CVE/Keystone volunteer clerical program, but due to lack of prior experience, required six months of hands-on training in the program to acquire sufficient skills for community-based employment. After six months of training, the subject sustained and maintained employment for at least three months or the remaining duration of the study.

Subject 4 was unemployed six months prior to utilizing service at CVE/Keystone and remained unemployed until six months after utilizing service. Six months after starting CVE/Keystone, the subject decided to participate in the CVE/Keystone volunteer clerical program in order to gain new skills for long term employment in the community. This subject was working in the volunteer program for at least six months or the remaining duration of this study. Subjects 5-9 were able to maintain employment for at least a duration of 3 months. AII of these subjects were unemployed prior to CVE/Keystone and participated in the 
CVE/Keystone volunteer clerical program for six months. After six months of training, the subjects were employed in the community and able to maintain employment over time. Subject 10 was unemployed or unable to maintain employment prior to CVE/Keystone. After three months of working in the volunteer program, this subject was able to maintain employment for at least six months or the duration of this study.

Subjects 11-14 were unemployed six months prior to vocational rehabilitation. These subjects utilized varying services at CVE/Keystone for six months before maintaining paid employment in the community. These subjects were able to maintain employment for at least three months or the remaining duration of this study.

Subjects 15-21 were unemployed six months prior to vocational rehabilitation. These subjects remained unemployed while utilizing service at CVE/Keystone for three months before sustaining work in the community. After obtaining paid employment, these subjects maintained employment for a duration of at least six months or until the close of this study.

Subjects 22-27 were unemployed or unable to maintain employment prior to utilizing service at CVE/Keystone. After starting vocational rehabilitation, these subjects maintained community-based employment for a duration of at 
least nine months or the remaining span of this study. Subjects 28-37 were unemployed six months prior to vocational rehabilitation and remained unemployed throughout the duration of this study.

Question 4: Is there a change in the wages earned six months prior to utilizing service at CVE/Keystone and three, six, and nine months after starting the vocational rehabilitation program?

The wage rate per hour was divided into nine increments in the data collection tool. A zero dollar amount indicated that the subject was working in a volunteer position in the CVE/Keystone Clerical Program. Table 4 illustrates the number of subjects receiving a particular wage rate at various time increments.

Six months prior to receiving vocational rehabilitation at CVE/Keystone, J. (3\%) subject was receiving a pay rate of \$4-5 per hour and $2(5 \%)$ subjects were receiving $\$ 6-7$ per hour. The remaining $34(92 \%)$ subjects were unemployed $(\$ 0 / \mathrm{hr})$. An average wage of $\$ .47$ per hour was calculated for the sample population $(N=37)$. Three months after receiving service at CVE/Keystone, 7 (19\%) subjects were receiving a pay rate of $\$ 4-5$ per hour and 8 (22\%) subjects were participating in the volunteer clerical program (\$0 per hour). The remaining 22 (59\%) subjects were unemployed 
Table 4

Frequency Distribution of Pay Rate of Subjects $\mathrm{N}=37$

\begin{tabular}{|c|c|c|c|c|c|}
\hline Wages & 6Mos Prior & 3Mos & After & 6Mos After & 9Mos After \\
\hline$\$ 4-5$ & $(3 \%)$ & 7 & $(198)$ & $11(308)$ & $15(41 \%)$ \\
\hline$\$ 6-7$ & $2(5 \%)$ & & 0 & $(8 \%)$ & $(19 \%)$ \\
\hline$\$ 8-9$ & 0 & & 0 & $2(5 \%)$ & $3(8 \%)$ \\
\hline$\$ 10-12$ & 0 & & 0 & 0 & $1(3 \%)$ \\
\hline$\$ 13-15$ & 0 & & 0 & 0 & 0 \\
\hline$\$ 16-18$ & 0 & & 0 & 0 & 0 \\
\hline$\$ 19-20$ & 0 & & 0 & 0 & 0 \\
\hline$\$ 20+$ & 0 & & 0 & 0 & 0 \\
\hline \$o (volunteer) & 0 & 8 & $(22 z)$ & $7(19 \%)$ & $1(38)$ \\
\hline Unemployed & $34 \quad(92 \%)$ & 22 & (59\%) & $14(38 \%)$ & $10 \quad(27 \%)$ \\
\hline Ave.Wage/hr. & $\$ .47 / \mathrm{hr}$. & $\$ .8$ & $5 / \mathrm{hr}$. & $\$ 2.32 / \mathrm{hr}$. & $\$ 4.04 / \mathrm{hr}$. \\
\hline
\end{tabular}


$(\$ 0 / h r)$. An average wage of $\$ .85$ per hour was tabulated for the sample.

Six months after vocational rehabilitation, 11 (30\%) subjects were receiving a pay rate of $\$ 4-5$ per hour; 3 ( $8 \%$ ) subjects were receiving $\$ 6-7$ per hour; 2 (5\%) subjects were receiving \$8-9 per hour. Seven (19\%) subjects were participating in the volunteer clerical program. The remaining 14 subjects (38\%) were unemployed. An average wage of $\$ 2.32$ per hour was calculated for the subjects. Nine months after starting vocational rehabilitation at CVE/Keystone, the following information was tabulated: 15 (41\%) subjects at $\$ 4-5$ per hour, 7 (19\%) subjects at \$6-7 per hour, $3(8 \%)$ subjects at $\$ 8-9$ per hour, $1(3 \%)$ subject at \$10-12 per hour, and 1 (3\%) subject in the volunteer clerical program. For the sample population, after nine months of receiving service from CVE/Keystone, an average wage of $\$ 4.04$ per hour was tabulated.

Question 5: Is there a change in the distribution of Social security benefits six months prior to utilizing service at CVE/Keystone and three, six, and nine months after starting the vocational rehabilitation program?

The data regarding the distribution of Social security benefits remained consistent throughout the duration of the study. The data are arranged in Table 5. The information was categorized into four headings: SSI, SSDI, Both SSI and 
SSDI, and Other. The "Other" category refers to those subjects who were not utilizing Social security, but who were receiving funds from another source (i.e. savings, family, military compensation). The data was subdivided to illustrate variances in the distribution of social security benefits with respect to gender.

of the 37 (100\%) subjects, 11 (30\%) were receiving SSI, 9 (24\%) were receiving SSDI, 11 (30\%) were receiving both SSI and SSDI, and 6 (16\%) were receiving funds from an outside source. Among the female subjects ( $N=16), 2$ (13\%) were receiving SSI, 4 (25\%) were receiving SSDI, 9 (56\%) were receiving both SSI and SSDI, and 1 (6\%) was receiving funds from an outside source. The male subjects ( $N=21$ ) had different results. Nine (43\%) subjects were receiving SSI, 5 $(24 \%)$ were receiving SSDI, 2 (9\%) were receiving a combination of SSI and SSDI, and 5 (24\%) were receiving funds from another source. 
Distribution of Social Security Benefits $N=37$

\begin{tabular}{cccccc}
\hline Responses & SSI & SSDI & Both SSI \& SSDI Other \\
\hline Female $(\mathbf{N}=16)$ & 2 & 4 & 9 & 1 \\
\hline Male $(\mathbf{N}=21)$ & 9 & 5 & 2 & 5 \\
\hline Total \# & 11 & 9 & 11 & 6 \\
\hline
\end{tabular}

\section{Distribution of Social Security Benefits}

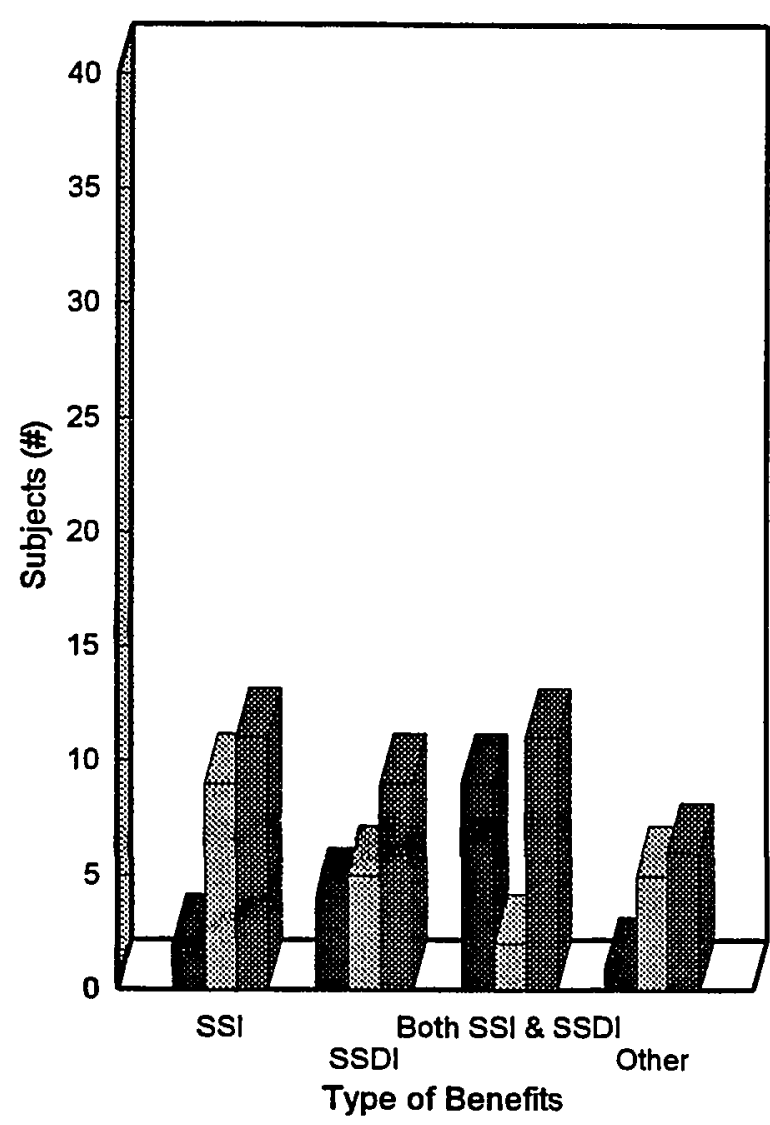

- Female $(\mathrm{N}=16)$ Male $(\mathrm{N}=21)$

Total \# 
CHAPTER 5

RESULTS, IMPLICATIONS AND RECOMMENDATIONS, SUMMARY

The purpose of this study was to explore and document employment outcomes for individuals with severe and persistent mental illness after utilizing vocational rehabilitation services delivered by CVE/Keystone. This chapter will concentrate on discussing the results of this study, describing implications of the study to the profession of occupational therapy and the CVE/Keystone program staff, and presenting recommendations for further study.

\section{Results}

The results of this study were:

1. After starting the CVE/Keystone vocational rehabilitation program, unemployment decreased and employment increased. Specifically, the number of subjects unemployed six months prior to starting vocational rehabilitation decreased from 34 (92\%) subjects to 11 (30\%) subjects. After three months of service, the number of subjects employed increased by $11 \%$ of the sample population. There was a $35 \%$ increase in the number of subjects employed six months after starting the vocational rehabilitation program. After nine months of vocational rehabilitation, the number of employed subjects increased by $63 \%$ of the sample population. In other words, 23 of the original 34 unemployed 
subjects sustained and maintained employment after starting the CVE/Keystone program. Results from this study indicate that the amount of subjects employed after utilizing vocational rehabilitation services delivered by CVE/Keystone increased after each three month time increment from $8 \%$ to $19 \%$ to $43 \%$ to $70 \%$ of the sample population. Hence, participation in the CVE/Keystone vocational rehabilitation program increased employment outcomes for the sample population. This data also indicated that subjects' participation in the CVE/Keystone volunteer clerical program may increase the potential for community-based employment since seven of the eight original subjects volunteering in the program maintained paid employment within the nine month duration of this study.

2. The average number of work hours per week for the subject sample increased after starting the CVE/Keystone vocational rehabilitation program. The average number of work hours per week increased by $1 \%$ or .5 work hours per week after three months of service and by $13 \%$ or 5.2 work hours per week after six months of service. After nine months of receiving services at CVE/Keystone the results of the study show a total increase of $28 \%$ or 11.3 work hours. In other words, $32 \%$ of the original 37 employed subjects were working at least 12.6 hours per week after nine months of vocational rehabilitation. The results from this study 
show that the rate of employment may increase by at least $28 \%$ after vocational rehabilitation at CVE/Keystone. As well, the rate of employment can increase throughout the duration of service for each subject.

3. The data indicated that the longevity of employment for subjects with severe and persistent mental illness may increase after a vocational rehabilitation program delivered by CVE/Keystone, since 27 (73\%) of the 37 subjects were able to continue or increase the duration of job maintained in the community within the time span of this study.

4. The average wage earned per hour three months after starting vocational rehabilitation increased by $\$ .38$ per hour. Six months after utilizing service, the average wage per hour increased by $\$ 1.85$ per hour. Overall, there was an average increase of $\$ 3.57$ per hour for the sample population after nine months of vocational rehabilitation at CVE/Keystone. This data indicated that the amount of wages earned per hour for individuals with severe and persistent illness increased after starting the CVE/Keystone vocational rehabilitation program. The amount of wages earned increased sequentially after each three month period of time from $1 \%$ after three months of service to $5 \%$ after six months of service to $9 \%$ after nine months of service.

Furthermore, after the nine months, seven of the original eight participants in the volunteer clerical 
program (\$0/hour) were maintaining paid employment. This data further indicated that the CVE/Keystone volunteer clerical program may assist clients in sustaining communitybased employment and thereby facilitate an increase in the wages earned through obtaining paid work.

5. The distribution of social security benefits six months prior to starting vocational rehabilitation at CVE/Keystone and three, six, and nine months after starting the program was consistent. There was no increase or decrease in the distribution of government assistance. This data indicated that the vocational rehabilitation program delivered by CVE/Keystone may successfully enroll and place persons who receive benefits from income-support programs in community-based employment.

This data further supported the idea that some benefit recipients are motivated to work, and that some employment programs like CVE/Keystone can increase earnings for clients by an amount that would not cause them to lose needed assistance. However, it can be inferred that with the increase in the rate of employment as measured by the number of work hours per week and the variable increase in the wage earned with paid work, there may be a decrease in the numerical amount of Social security benefits distributed due to changes in need and eligibility.

Based on the results of this study implications were 
identified and recommendations for further research were made.

\section{Implications and Recommendations}

Severe and persistent mental illness is a long term health care issue in our society. To effectively treat this population, it is important for occupational therapists to provide assistance and guidance with issues in day to day community living. Work is a large part of this day to day existence.

The philosophy of occupational therapy states that people have a right to become as independent as possible and has a need to perceive oneself as a productive member of society. Individuals with severe and persistent mental illness, like all people, should be given the opportunities to achieve goals of independence and productivity. As implicated in this study, community-based employment is one very successful way in which these goals may be achieved.

Specifically, the results indicated that the CVE/Keystone vocational rehabilitation program improved employment for this population. Seventy percent of the subjects who were unemployed when they started CVE/Keystone were employed nine months later. In fact, the data showed that the employment outcomes increased with each three month period of time. As well, the wages earned and the number of 
hours employed per week for the subjects increased sequentially for each time period. In addition, almost all of the clients remained employed after nine months of service. There was no reduction of Social security benefits indicated. Furthermore, the data showed that those individuals who were volunteering in the CVE/Keystone Clerical Program moved into paid positions in the community. Thj.s data directly supports the premise that Transitional Employment Programs and volunteer work are a successful and useful tool in the employment process.

As a result of this research, a number of recommendations can be made for further research. 1. CVE/Keystone may use the documented information to analyze the cost effectiveness of service for reference or for viewing by third party payers and managed care organizations. 2. A follow up study could be conducted to determine if the participants were able to maintain paid employment in the community outside the time limitations of this study. 3. A study could be conducted that included all participants of the CVE/Keystone vocational rehabilitation program rather than limiting to specific subject criteria as in this study. 4. A study could be conducted that examined the role and effectiveness of occupational therapy assessment for individuals with severe and persistent mental illness 
utilizing service at CVE/Keystone.

5. A study that further investigated the relationship of volunteer work to future paid employment could be conducted. 6. A study could be conducted that investigated the success of specific interventions in the CVE/Keystone program. 7. If a computerized tracking system was developed at CVE/Keystone that incorporated data regarding the specific numerical amount of social security benefits received over time, a long term follow up study could be conducted to investigate this data.

8. A computerized data system would also greatly aid in similar correlational investigations. A researcher could collect additional data and investigate correlations with employment outcomes (i.e. years in the system, Allen's Cognitive level (1982), membership in specific programs, or previous skills and length of experience).

\section{Summary}

CVE/Keystone is a partnership that provides an environment in which clients are given the opportunity to make independent choices regarding vocational pursuits in the community. This study was conducted to examine employment outcomes for individuals with severe and persistent mental illness after vocational rehabilitation delivered by CVE/Keystone was utilized.

The results of this study indicated that the number of 
subjects who were employed at CVE/Keystone increased after vocational rehabilitation was utilized. In addition, there was an increase in the number of work hours per week and in the amount of wages earned after vocational rehabilitation at CVE/Keystone. The longevity of employment also improved after utilizing CVE/Keystone vocational rehabilitation services. There was no change in the distribution and utilization of social security benefits for any of the subjects.

Based on the results of this study, it is apparent that the CVE/Keystone vocational rehabilitation program is influential in increasing employment outcomes for individuals with severe and persistent mental illness. 
References

Allen, C. (1982) Independence through activity: The practice of occupational therapy (Psychiatry). American Journal of Occupational Therapy, 36, 731-739.

American Occupational Therapy Association (1994). Uniform terminology for occupational therapy-Third edition. American Journal of Occupational Therapy, 48, 1047-1054.

Americans With Disabilities Act of 1990 (Public Law 101-336), 42 U. S. C. \& 12101.

Andrew, H., Barker, J., Pittman, J., Mars, L., Straining, E., \& Larks, N. (1992). National trends in vocational rehabilitation: A comparison of individuals with physical disabilities and individuals with psychiatric disabilities. Journal of Rehabilitation, 58 (1), 7-16.

Anthony, W. A. (1982). Explaining "psychiatric rehabilitation" by an analogy to "physical rehabilitation." Psychosocial Rehabilitation Journal, 5, 61-66.

Anthony, W. A., \& Blanch, A. (1987). Supported employment for persons who are psychiatrically disabled: An historical and conceptual perspective. Psychosocial Rehabilitation Journal, 11(2), 5-23.

Bailey, D. M. (1968). A work program in psychiatry. American Journal of Occupational Therapy, 22, 311-2. 
Bockoven, J. S. (1971). Legacy of moral treatment$1800^{\prime} \mathrm{s}$ to 1910. American Journal of Occupational Therapy. 25, 223-225.

Bond, G. R. (1987). Supported employment as a modification to the transitional employment model for clients with psychiatric disorders. Psychosocial Rehabilitation Journal, 11 (2) 55-71.

Bond, G. R. (1988). Rehabilitation programs and outcomes. In M. D. Farkas \& W. A. Anthony (Eds.), Psychiatric Rehabilitation Programs (pp. 123-127). Baltimore: John Hopkins University Press.

Bond, G. R., \& Boyer, S. L. (1988). Rehabilitation programs and outcomes. In J. A. Ciardiello \& M. D. Bell (Eds.), Vocational rehabilitation of persons with prolonged mental illness (pp. 231-263). Baltimore: John Hopkins University Press.

Christiansen, C., \& Baum, C. (1991). Occupational therapy: Overcoming human performance deficits (pp. 14-15). NJ : Slack.

Cromwell, F. S. (1966). Occupational therapistObserver or educator. Canadian Journal of Occupational Therapy, 33, 63-71.

Dart, J. (1990). ADA: Landmark declaration of equality. Worklife, $3(3), 1$. 
Delbecq, A. L., Van de Ven, A. H., \& Gustafason, D. H. (1975). Group technigues for program planning: A quide to nominal group and delphi processes. IL: Scott, Foresman and Company .

Department of Health and Human Services. (1984). A program inspection on transition of developmentally disabled adults from school to adult services. Richard P. Kusserow, Inspector General, April 13.

Developmental Disabilities Act of 1984 (Public Law 98527), 42 U. S. C. \& 6000-6009.

Dulay, J. \& Steichen, M. (1983). Transitional employment for the chronically mentally ill. Occupational Therapy in Mental Health, 2(3), 65-77.

Ethridge, D. A., (1968). Prevocational assessment of rehabilitation potential of psychiatric patients. American Journal of Occupational Therapy, 22, 161-167.

Fidler, G. S. (1966). A second look at work as a primary force in rehabilitation and treatment. American Journal of Occupational Therapy, 20, 72-74.

Frey, J. L. (1994). Long term support: The critical element to sustaining competitive employment: Where do we begin? Psychosocial Rehabilitation Journal, 17, 127-134. Garson, B. (1975). All the livelong day: The meaning and demeaning of routine work. Garden City, NY: Doubleday. 
Goldman, H. H., Gattozzi, A. A., \& Taube, C. A. (1981). Defining and counting the chronically mentally ill. Hospital and Community Psychiatry, 32, 259.

Hagedorn, R. (1992) . Occupational therapy: Foundations for practice. Edinburgh, UK: Churchill Livingstone.

Harvey-Krefting, L. (1985). The concept of work in occupational therapy: A historic review. American Journal of Occupational Therapy, 39, 301-307.

Heard, C. (1977). Occupational role acquisition. American Journal of Occupational Therapy, 31, 243-247. Hopkins, H. (1983). An historical perspective on occupational therapy. In H. Hopkins \& H. Smith (Eds.), Willard \& Spackman's occupational therapy (pp. 27-41). Philadelphia: Lippencott.

Johnson, J., \& Kielhofner, G. (1983). Occupational therapy in the health care system of the future. In $G$. Kielhofner (Ed.), Health through occupation: Theory and practice in occupational therapy (pp. 87-95). Philadelphia: Davis.

Kaplan, M. I., \& Sadock, B. J. (Eds.). (1981). Modern synopses of comprehensive textbook of psychiatry. Baltimore, MD: Williams \& Wilkins.

Kester, D. (1983). Prevocational training. In H. Hopkins \& H. Smith (Eds.), Willard \& Spackman's occupational therapy (pp. 251-257). Philadelphia: Lippincott. 
Kielhofner, G. (1983). Occupation. In H. Hopkins \& H. Smith (Eds.), Willard \& Spackman's occupational therapy (pp. 31-42). Philadelphia: Lippincott.

Kielhofner, G., \& Burke, J. (1980). A model of human occupation. The American Journal of Occupational Therapy, 34, $572-581$.

Kielhofner, G. \& Burke, J. (1983). The evolution of knowledge and practice in occupational therapy: Past, present, and future. In G. Kielhofner (Ed.), Health through occupation: Theory and practice in occupational therapy ( $p$. 89-95). Philadelphia: Davis.

Lamb, R. \& Edelson, (1976). The carrot and the stick:

Inducing local programs to serve long-term patients.

Community Mental Health Journal, 12, 137-144.

Louis Harris \& Associates. (1987). The ICD survey II: Employing disabled Americans: A nationwide survey of 920 employers (Study No. 864009). New York: Author.

Marshall, E. (1985). Looking back. American Journal of Occupational Therapy, 39, 297-331.

McCue, M., \& Katz-Garris, L. (1983). The severely disabled psychiatric patient and adjustment to work. Journal of Rehabilitation, 49, 52-58.

Meyer, A. (1977). The philosophy of occupational therapy. American Journal of Occupational Therapy, 31, 639642 . 
Patti, G. C., \& Morrison, G. (1982). Enabling the disabled. Harvard Business Review, 60, 152-160.

Reed, K. (1984). Models of practice in occupational therapy. Baltimore, MD: Williams \& Wilkins.

Reed, K. L., \& Saunderson, S. R. (1983). Concepts of occupational therapy. Baltimore, MD: Williams \& Wilkins.

Rehabilitation Act of 1973 (Public Law 93-112), $29 \mathrm{U}$. S. C. \& 794 .

Robinson, I. M. (1981). The mists of time. Canadian Journal of Occupational Therapy, 48, 145-151.

Skelley, T. J. (1980). National developments in rehabilitation: A rehabilitation services perspective. Rehabilitation Counseling Bulletin, 24, 22-33.

Spooner, F., Algozzine, B., \& Saxon, J. (1980). The efficacy of vocational rehabilitation with mentally ill persons. Journal of Rehabilitation, 46 (4), 62-66.

Stauffer, D. L. (1986). Predicting successful employment in the community for people with a history of chronic mental illness. Occupational Therapy in Mental Health, 6 (2), 31-39.

Thornton, C., \& Maynard, R. (1989). The economics of transitional employment and supported employment. In $M$. Berkowitz \& M. A. Hill (Eds.), Disability and the labor market: Economic problems, policies, and programs (pp. 142 170). New York: ILR Press. 
Tiffany, E. (1983). Psychiatry and mental health. In H. Hopkins \& H. Smith (Eds.), Willard \& Spackman's occupational therapy (pp. 268-283). Philadelphia: Lippincott.

Torrey, E. F. (1988). Surviving schizophrenia: A family manual. New York: Harper \& Row.

Wehman, P. \& Kregal, J. (1985). A supported work approach to competitive employment of individuals with moderate and severe handicaps. Journal of the Association for Persons with Severe Handicaps, 10 (1), 3-11.

Woodside, H. H. (1971). The development of occupational therapy, 1910-1929. American Journal of Occupational Therapy, 25, 226-230.

Yankelovich, D. (1981). The meaning of work. In J. O'Toole, J. L. Scheiber, \& L. C. Wood (Eds.), Working: Changes and choices (pp. 33-34). New York: Human Sciences Press. 
Appendix A

Sample Instrument 


\section{DEMOGRAPHICS}

1. Sex:

M

2. Age:

$\begin{array}{ll}-16-20 & -40-49 \\ -21-29 & -50-59 \\ -30-39 & -60+\end{array}$

\section{MONTHS PRIOR TO STARTING PROGRAM}

1. Is the client employed? _yes _no

2. If so, where?

3. If so, number of hours employed each week?

$\begin{array}{ll}-1-4 & -{ }^{21-25} \\ -6-10 & -26-30 \\ -11-15 & -31-35 \\ -16-20 & -36-40\end{array}$

4. If so, wages earned per hour each week?

$\begin{array}{lr}-\$ \text { volunteer } & -\$ 10-12 \\ -\$ 4-5 & -\$ 13-15 \\ -\$ 6-7 & -\$ 16-18 \\ -\$ 8-9 & -\$ 19-20\end{array}$

5. Is the client receiving social security Benefits? Lyes _no

6. What type of benefits? _SSI _SSDI _Both _Other

7. Amount of benefits received per month? 


\section{3, 6, and 9 MONTHS AFTER STARTING PROGRAM}

1. Is the client employed? -yes no

2. If so, where?

3. If so, number of hours employed each week?

$\begin{array}{lr}-1-5 & -21-25 \\ -6-10 & -26-30 \\ -11-15 & -31-35 \\ -16-20 & -36-40\end{array}$

4. If so, wages earned per hour each week?

$\begin{array}{lr}-\$ 0 \text { volunteer } & -\$ 10-12 \\ -\$ 4-5 & -\$ 13-15 \\ -\$ 6-7 & -\$ 16-18 \\ -\$ 8-9 & -\$ 19-20\end{array}$

5. Is the client receiving Social security Benefits? -yes _no

6. What type of benefits? _SSI _SSDI _Both _Other

7. Amount of benefits received per month? 
Appendix B

Instrument Used for Data Collection 
Open Orientation Date: Intake Interview Date:

1. Sex:

\section{DEMOGRAPHICS}

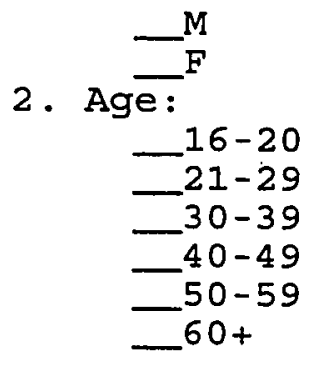

6 MONTHS PRIOR TO STARTING PROGRAM

1. Is the client employed?

2. If so, number of hours employed each week?

$\begin{array}{ll}1-4 & \\ -6-10 & 26-\overline{30}^{21-25} \\ -11-15 & 31-35 \\ -16-20 & 36-40\end{array}$

3 . If so, wages earned per hour each week?

$\begin{aligned} & \$ \text { volunteer } \\ - & \$ 4-5 \\ - & 6-7 \\ - & 8-9\end{aligned}$
$\$ 10-12$

$\$ 13-15$

$\$ 16-18$

$\$ 19-20$

4. Is the client receiving Social Security Benefits?

-yes no

5. What type of benefits? _SSI _SSDI _Both _other 


\section{MONTHS AFTER STARTING PROGRAM}

1. Is the client employed? -yes no

2. If so, number of hours employed each week?

$\begin{array}{ll}1-5 & -21-25 \\ -6-10 & 26-30 \\ -11-15 & 31-35 \\ -16-20 & -36-40\end{array}$

3 . If so, wages earned per hour each week?

$\$ 0$ volunteer

$\$ 4-5$

$\$ 6-7$

$\$ 8-9$

$\$ 10-12$

$\$ 13-15$

$\$ 16-18$

$\$ 19-20$

4. Is the client receiving Social Security Benefits?

5. What type of benefits? no SSI SSDI Both other

\section{MONTHS AFTER STARTING PROGRAM}

1. Is the client employed? yes - no

2. If so, number of hours employed each week? $-1-5$ -6-10

$11-15$

$-21-25$

$16-20$

$-26-30$

$-31-35$

so, wages earned per hour each week?

-\$0 volunteer

$-\$ 4-5$

$\$ 6-7$

$\$ 8-9$

$\$ 10-12$

$\$ 13-15$

$\$ 16-18$

$\$ 19-20$

4. Is the client receiving Social Security Benefits?

5. Yes no

5. What type of benefits? _SSI _SSDI _Both _other

2. If so, number of hours employed each week?

\section{MONTHS AFTER STARTING PROGRAM}

$\begin{array}{ll}-1-5 & -21-25 \\ -6-10 & 26-30 \\ -11-15 & -31-35 \\ -16-20 & -36-40\end{array}$

3. If so, wages earned per hour each week?

_\$o volunteer

-\$4-5

$\$ 6-7$

$\$ 8-9$

$\$ 10-12$

$\$ 13-15$

$\$ 16-18$

$\$ 19-20$

4. Is the client receiving Social Security Benefits? yes

5. What type of benefits? _SSI _SSDI _Both _other 